\title{
Urban Road Safety and Crash Severity during the 2020 COVID-19 Pandemic: The Case of Seattle, WA
}

\author{
Haifeng (Felix) Liao ${ }^{1}$ (1) 8 , Michael Lowry ${ }^{2}$ (1) \\ ${ }^{1}$ Geography and Geological Sciences, University of Idaho, ${ }^{2}$ Civll and Environmental Engineering, University of Idaho \\ Keywords: traffic safety, collision severity, crashes, quasi-difference-in-differences analysis, spatial-temporal analysis, covid-19 \\ https://doi.org/10.32866/001c.30007
}

Findings

\begin{abstract}
Teleworking and lockdown measures implemented during the COVID-19 pandemic have resulted in reduced traffic flows and fewer cars at risk of collision on roads. The present study presents an analysis of the pandemic's impact on traffic safety and crash severity in the city of Seattle, WA. We found increased shares of speeding-related, angle-, and head-on collisions and relatively more collisions occurring during off-peak hours. Results of quasi-difference-indifferences modeling further suggest that collisions occurring during the postlockdown period have had a higher probability of being fatal or resulting in severe injuries, compared to what would be expected in the absence of the pandemic.
\end{abstract}

\section{QUESTIONS}

The year 2020 witnessed reduced traffic flows in American cities due to public health responses (e.g., lockdowns) and teleworking during the COVID-19 pandemic. The decrease in traffic volumes, however, does not necessarily result in relatively fewer traffic-related fatalities or severe injuries. Drawing upon the case of Seattle, a U.S. city impacted early by the COVID-19 outbreak and throughout the pandemic, the present study aims to examine changes in crash patterns and the level of severity during the pandemic. We sought to answer the following questions:

- How did the time of the day, the spatial distribution, and the types of vehicle crashes in the city of Seattle change during the 2020 COVID-19 pandemic?

- How did the pandemic affect crash severity in the year 2020 compared with that in the previous year? And would these impacts vary during different phases of the pandemic?

\section{METHODS AND DATA}

We collected a motor vehicle collision dataset from the City of Seattle Open Data program. The dataset contains information regarding crashes that occurred between January 1, 2019, and December 31, 2020, as submitted by law enforcement. During the study period, there were a total of 14,122 crashes in the city of Seattle. The crash data include the number of motorists, passengers, pedestrians, and cyclists involved, major contributing factors (e.g., speeding), crash types (e.g., head-on, rear-end, left-turn, sideswipe, etc.); severity (i.e., property damage only or no injury, injury, fatal or severe injury); and others (e.g., location, date, and time of the day). 

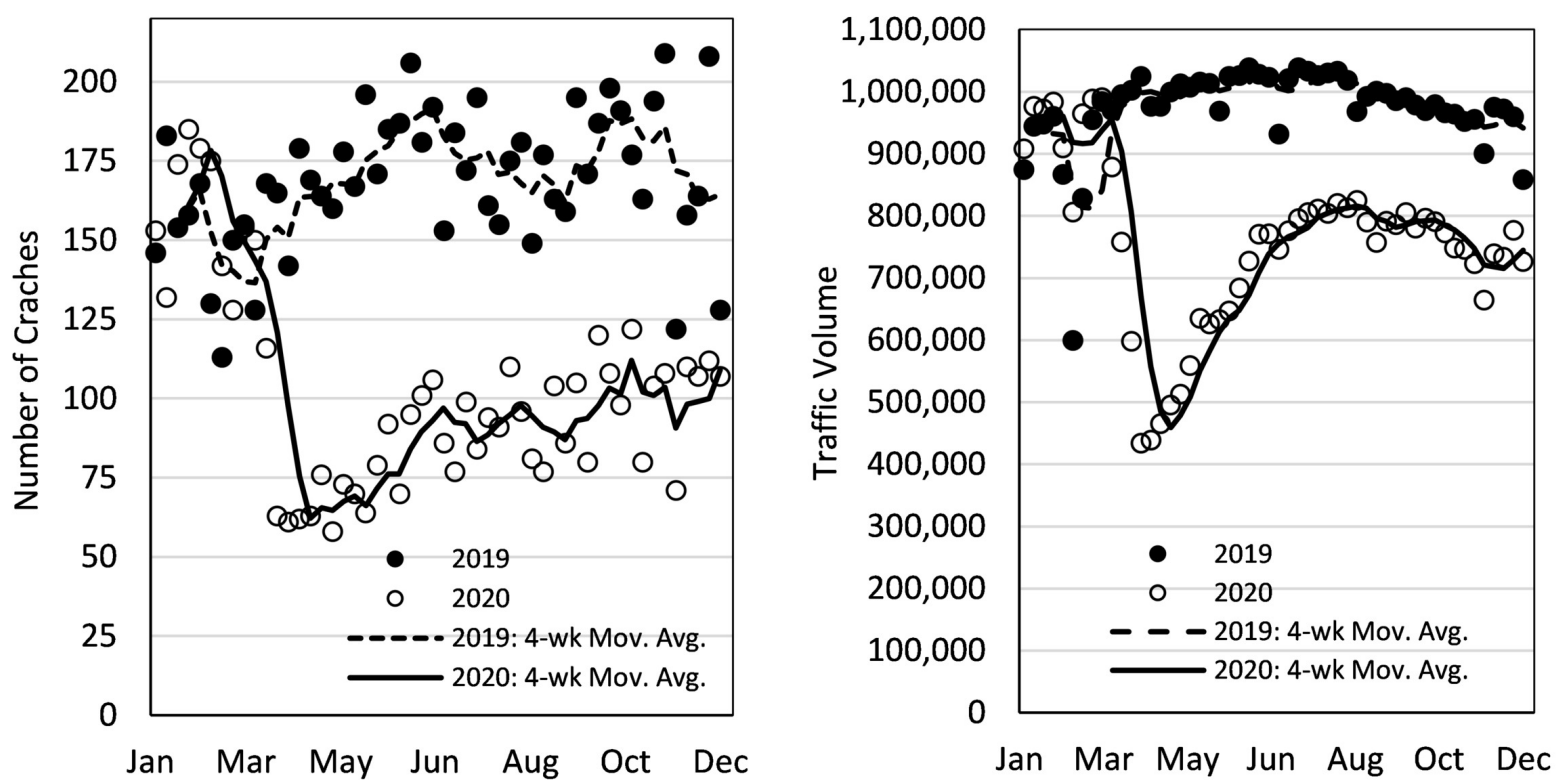

Figure 1. Weekly crash counts(left) and average daily traffic volume(right) in the city of Seattle in 2019 and 2020

Notes: Traffic flow data in Seattle were retrieved from loop detectors at major highway entrances of Interstates I-5 and I-90, which measure commuter traffic to or from the city of Seattle (Bian et al. 2021).

Besides a descriptive analysis of crash characteristics before and after the pandemic, the study employed a multinomial logistic regression model (Stiles et al. 2021), in conjunction with a difference-in-differences or DID approach, to quantify the impact of the pandemic on crash severity. The empirical model assumes that in the absence of the pandemic, temporal changes in crash severity before and after the onset of the COVID-19 outbreak would be essentially the same in 2020. Therefore, the year 2020 is considered as the "treatment group," and the periods after the disruption in both 2019 and 2020 are considered as the "aftertreatment periods" (Zhang and Tang 2021; Vandoros 2021). A similar quasi-DID model with previous years as a control group has been utilized in previous studies when a control group is not available during a global pandemic (Vandoros 2020, 2021; Zhang and Tang 2021). Two "aftertreatment periods," specifically March-May and June-December, were used based on the timeline of the two phases of the pandemic (Jiao and Azimian 2021). Daily average temperature and monthly dummies were also included to control for seasonal conditions (Doucette et al. 2021; Li et al. 2021).

\section{FINDINGS}

Figure 1 shows weekly trends of traffic volumes and motor vehicle collisions' counts in the city of Seattle in 2019 and 2020. There appeared to be steep declines in total crashes and traffic volumes during the period when the stayat-home order was in effect (i.e., from March 3 to May 31st). However, the rebound of vehicle volumes may have started as soon as early April, nevertheless, they remained 20-30\% lower compared to 2019 throughout the pandemic. 
Table 1. Descriptive statistics of crashes in the city of Seattle during 2019-2020

\begin{tabular}{|c|c|c|c|c|c|c|}
\hline & \multicolumn{3}{|c|}{2019} & \multicolumn{3}{|c|}{2020} \\
\hline & $\begin{array}{l}\text { January- } \\
\text { February }\end{array}$ & $\begin{array}{l}\text { March- } \\
\text { May }\end{array}$ & $\begin{array}{l}\text { June- } \\
\text { Dec. }\end{array}$ & $\begin{array}{l}\text { January- } \\
\text { February }\end{array}$ & $\begin{array}{l}\text { March- } \\
\text { May }\end{array}$ & $\begin{array}{l}\text { June- } \\
\text { Dec. }\end{array}$ \\
\hline Total crashes & 1,264 & 2,187 & 5,333 & 1,363 & 1,061 & 2,914 \\
\hline Mean crashes per day & 24.06 & 23.77 & 24.92 & 23.10 & 11.53 & 13.62 \\
\hline Daily traffic volumes & 879,497 & 998,570 & 986,570 & 946,707 & 599,932 & 768,175 \\
\hline $\begin{array}{l}\text { No injury or property damage } \\
\text { only crashes (\%) }\end{array}$ & 66.06 & 64.52 & 64.32 & 68.97 & 62.11 & 62.83 \\
\hline Injury crashes (\%) & 32.04 & 33.01 & 33.68 & 29.42 & 34.59 & 33.97 \\
\hline Fatal or severe-injury crashes (\%) & 1.90 & 2.47 & 2.01 & 1.61 & 3.30 & 3.19 \\
\hline $\begin{array}{l}\text { Peak hours ( } 6 \text { am }-9 \text { am or } 4 \text { pm - } \\
7 \text { pm, \%) }\end{array}$ & 41.77 & 43.94 & 43.62 & 45.56 & 37.04 & 39.84 \\
\hline Weekend (\%) & 20.02 & 23.64 & 23.53 & 22.74 & 23.75 & 23.20 \\
\hline Speeding (\%) & 4.75 & 2.79 & 4.22 & 4.84 & 9.61 & 5.94 \\
\hline Angles (\%) & 19.62 & 20.48 & 20.27 & 21.94 & 22.05 & 22.72 \\
\hline Head On (\%) & 1.74 & 0.87 & 1.03 & 2.05 & 1.70 & 1.58 \\
\hline Cycles (\%) & 2.85 & 5.17 & 4.37 & 2.35 & 3.58 & 3.81 \\
\hline Pedestrian (\%) & 6.65 & 5.07 & 6.08 & 6.60 & 3.68 & 4.32 \\
\hline Rear Ended (\%) & 16.69 & 17.06 & 16.89 & 17.98 & 15.65 & 16.71 \\
\hline Parked Car (\%) & 21.04 & 21.12 & 19.05 & 17.90 & 20.83 & 17.02 \\
\hline Sideswipe (\%) & 10.36 & 11.43 & 12.15 & 11.74 & 8.77 & 9.81 \\
\hline Left Turn (\%) & 7.52 & 7.45 & 7.84 & 6.53 & 6.31 & 7.55 \\
\hline Right Turn (\%) & 1.50 & 1.55 & 1.28 & 1.69 & 1.70 & 1.61 \\
\hline Other (\%) & 12.03 & 9.69 & 11.04 & 11.23 & 15.83 & 14.86 \\
\hline
\end{tabular}

As illustrated in Table 1, speeding-related crashes accounted for $9.6 \%$ of total collisions during the lockdown period of March-May, compared with $2.8 \%$ in the previous year; meanwhile, the percentage of head-on collisions doubled during the lockdown period and angles-type collisions' shares also increased. In contrast, the shares of collisions involving pedestrians or cyclists declined from $\sim 9-10 \%$ in the previous year to $7-8 \%$, as did the percentage of crashes where vehicles were rear-ended or sideswiped (Table 1). Specifically, the severity level of these collisions or the share of severe-injury or fatal crashes increased, with 3.3\% and 3.2\% in March-May and June-December in 2020 respectively, compared with $2.5 \%$ and $2.0 \%$ during the same periods in 2019 .

As shown in Figure 2, crashes were also more likely to occur before or after the peak travel times throughout the pandemic in 2020. Moreover, we performed a kernel density estimation on crash locations during the two phases of the pandemic (Figure 3). Despite decreases of kernel densities in 2020, the spatial distribution of crashes appeared similar to the patterns before the pandemic. However, there was a new hotspot in southwestern areas of the city, and crash locations appeared to be spatially more dispersed. 

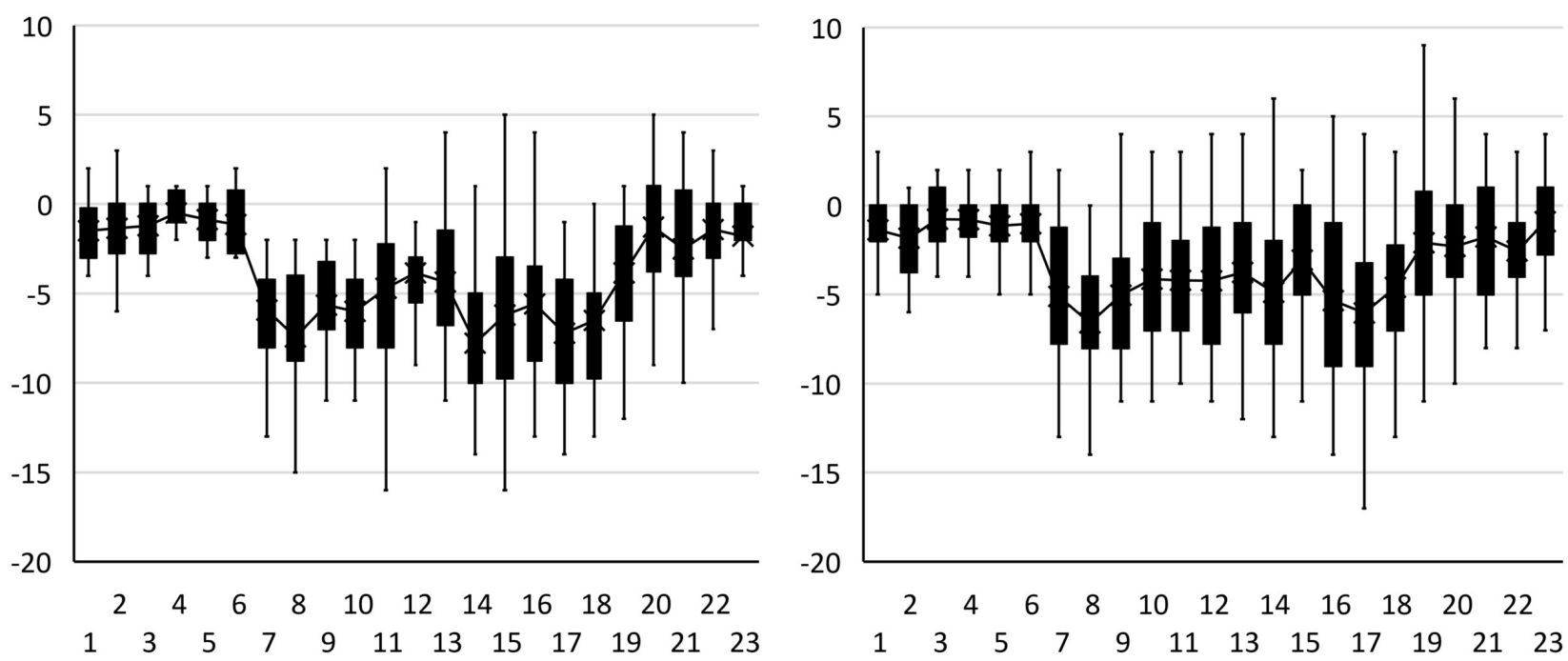

Figure 2. Change of weekly counts of crashes in Seattle grouped by different hours of a day: March-May or the lockdown period (left) and June-December or the post-lockdown period (right)

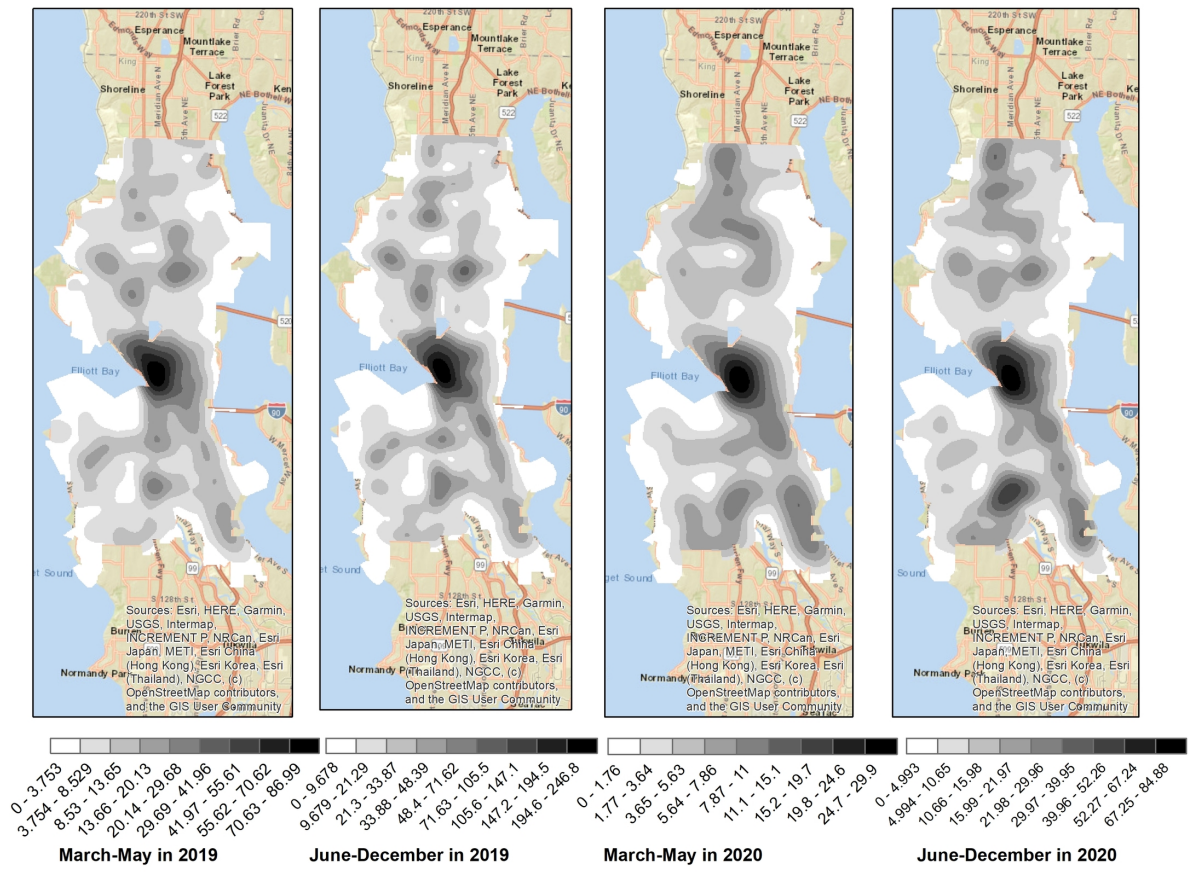

Figure 3. Kernel densities of crash locations in the city of Seattle during 2019-2020

The results of DID- or difference-in-differences- based multinomial logistic regression on crash severity (i.e., no injury, injury, severe injury or fatal) are summarized in Table 2. First, we found that compared to what would be expected in the absence of the pandemic, collisions occurring during the lockdown period of March-May had a significantly higher probability of being associated with injuries (RRR: 1.504, 95\% CI: 1.16-1.95). More importantly, when controlling for other collision attributes, after the easing of the lockdown 
Table 2. DID-based multinomial logistic regression results, crash severity, 2019-2020

\begin{tabular}{|c|c|c|c|c|c|c|}
\hline & \multicolumn{3}{|c|}{$\begin{array}{l}\text { Probability of a crash associated } \\
\text { with injury }\end{array}$} & \multicolumn{3}{|c|}{$\begin{array}{l}\text { Probability of a crash associated with serious } \\
\text { injury or fatality }\end{array}$} \\
\hline & Coef. & Sig. & RRR & Coef. & Sig. & RRR \\
\hline \multicolumn{7}{|l|}{$\begin{array}{l}\text { Reference group: no injury or property } \\
\text { damage only }\end{array}$} \\
\hline $\begin{array}{l}\text { DID interaction term } 1 \text { (lockdown or } \\
\text { March-May) }\end{array}$ & 0.408 & $* * *$ & 1.504 & 0.598 & & 1.818 \\
\hline $\begin{array}{l}\text { DID interaction term } 2 \text { (post-lockdown } \\
\text { or June-Dec.) }\end{array}$ & 0.287 & $* * *$ & 1.332 & 0.908 & $* *$ & 2.479 \\
\hline Treatment period dummy (March-May) & -0.067 & & 0.935 & 0.491 & & 1.635 \\
\hline Treatment period dummy (June-May) & -0.121 & & 0.886 & -0.164 & & 0.849 \\
\hline Treatment group dummy (2020) & -0.219 & $* *$ & 0.804 & -0.283 & & 0.754 \\
\hline Peak hours & -0.038 & & 0.962 & -0.004 & & 0.996 \\
\hline Weekends & 0.119 & ** & 1.126 & 0.354 & $* * *$ & 1.424 \\
\hline Speeding & 0.371 & *** & 1.449 & 1.725 & *** & 5.610 \\
\hline Cycles & 2.430 & $* * *$ & 11.358 & 3.482 & $* * *$ & 32.536 \\
\hline Pedestrian & 2.310 & & 1.030 & 4.219 & $* * *$ & 67.985 \\
\hline Head On & 0.030 & $* * *$ & 10.079 & 1.430 & *** & 4.180 \\
\hline Rear Ended & 0.014 & & 1.014 & -1.295 & $* * *$ & 0.274 \\
\hline Parked Car & -1.936 & $* * *$ & 0.144 & -1.972 & $* * *$ & 0.139 \\
\hline Sideswipe & -1.252 & $* * *$ & 0.286 & -1.651 & $* * *$ & 0.192 \\
\hline Left Turn & 0.106 & & 1.112 & 0.734 & $* * *$ & 2.083 \\
\hline Right Turn & -0.777 & $* * *$ & 0.460 & -0.631 & & 0.532 \\
\hline Other & -0.762 & $* * *$ & 0.467 & 0.048 & & 1.049 \\
\hline Daily average temperature & 0.017 & $* *$ & 1.017 & -0.006 & & 0.994 \\
\hline Pseudo R square & .170 & & & & & \\
\hline
\end{tabular}

Notes: Robust SEs were used for a more conservative estimate of the RRR or relative risk ratios; DID=difference-in-differences. Climate data were retrieved from the National Climate Data Center's climate data online database, and from weather stations in Seattle. Coef.=coefficient; Sig.=Significance.

order in June, the likelihood of a crash being fatal or resulting in severe injuries significantly increased by 2.48 times (95\% CI: $1.25-4.93$ ). Second, the severity level of crashes remained significantly associated with a wide array of other factors such as speeding, weekday vs. weekend driving, pedestrian-, or cyclist involvement, or being a head-on collision (Table 2).

In conclusion, our case study of Seattle suggests that during the 2020 COVID-19 pandemic, despite a substantial decline in the total number of crashes, the remaining crashes had a higher probability of being fatal or resulting in severe injuries compared with what would have been otherwise expected. This finding could be attributed to riskier driving behaviors such as speeding amid the pandemic, as found in other studies (Lee, Porr, and Miller 2020). The study provides additional evidence that during the pandemic, there were also relatively fewer collisions involving pedestrians or bicyclists, whereas more collisions were found to be angle- or head-on crashes, and crashes that occur during the post-lockdown period were more likely to be correlated with adverse outcomes (e.g., fatalities). Future studies on the pandemic's impact on 
road safety should pay more attention to changes in vehicle types involved in these collisions, or the ways in which possible higher speed due to lower traffic volumes during the pandemic would affect crash severity if additional datasets or information (e.g., vehicle speed, speed limits or the distribution of traffic signals) are available.

\section{Acknowledgments}

This study was funded by a grant from Pacific Northwest Transportation Consortium (Pac Trans), USDOT Transportation Center for Federal Region 10 under the award \#69A3551747110.

\section{Data and codes}

The data and codes used in this research can be downloaded from the following GitHub repository NYC_SEA_Crashes_COVID19.git https://github.com/felixgeo/ 


\section{REFERENCES}

Bian, Zilin, Fan Zuo, Jingqin Gao, Yanyan Chen, Sai Sarath Chandra Pavuluri Venkata, Suzana Duran Bernardes, Kaan Ozbay, Xuegang (Jeff) Ban, and Jingxing Wang. 2021. "Time Lag Effects of COVID-19 Policies on Transportation Systems: A Comparative Study of New York City and Seattle." Transportation Research Part A: Policy and Practice 145 (March): 269-83. https://doi.org/ 10.1016/j.tra.2021.01.019.

Doucette, Mitchell L, Andrew Tucker, Marisa E Auguste, Amy Watkins, Christa Green, Flavia E Pereira, Kevin T Borrup, David Shapiro, and Garry Lapidus. 2021. "Initial Impact of COVID-19's Stay-at-Home Order on Motor Vehicle Traffic and Crash Patterns in Connecticut: An Interrupted Time Series Analysis.” Injury Prevention 27 (1): 3-9. https://doi.org/10.1136/ injuryprev-2020-043945.

Jiao, Junfeng, and Amin Azimian. 2021. "Exploring the Factors Affecting Travel Behaviors during the Second Phase of the COVID-19 Pandemic in the United States." Transportation Letters 0 (0): 1-13. https://doi.org/10.1080/19427867.2021.1904736.

Lee, Jinhyung, Adam Porr, and Harvey Miller. 2020. "Evidence of Increased Vehicle Speeding in Ohio’s Major Cities during the COVID-19 Pandemic.” Findings, June, 12988. https://doi.org/ 10.32866/001c.12988.

Li, Li, Lucas M. Neuroth, Edward Valachovic, David C. Schwebel, and Motao Zhu. 2021. "Association Between Changes in Social Distancing Policies in Ohio and Traffic Volume and Injuries, January Through July 2020.” JAMA 325 (10): 1003. https://doi.org/10.1001/ jama.2020.25770.

Stiles, Jonathan, Armita Kar, Jinhyung Lee, and Harvey J. Miller. 2021. "Lower Volumes, Higher Speeds: Changes to Crash Type, Timing, and Severity on Urban Roads from COVID-19 Stay-atHome Policies." Transportation Research Record, September, 03611981211044454. https://doi.org/10.1177/03611981211044454.

Vandoros, Sotiris. 2020. "Excess Mortality during the Covid-19 Pandemic: Early Evidence from England and Wales.” Social Science Er Medicine 258 (August): 113101. https://doi.org/10.1016/ j.socscimed.2020.113101.

- - . 2021. "COVID-19, Lockdowns and Motor Vehicle Collisions: Empirical Evidence from Greece.” Injury Prevention, May. https://doi.org/10.1136/injuryprev-2020-044139.

Zhang, Tuo, and Maogang Tang. 2021. "The Impact of the COVID-19 Pandemic on Ambient Air Quality in China: A Quasi-Difference-in-Difference Approach.” International Journal of Environmental Research and Public Health 18 (7): 3404. https://doi.org/10.3390/ijerph18073404. 